along without glasses." She had trouble the first week getting accustomed to the prisms.

This case has more than ever impressed me with the necessity of watching before making a positive diagnosis in heterophorias.

Finally I wish to emphasize the fact that operations should not be done simply to change measurements but should be done to relieve symptoms. Proper study of cases should enable one to determine whether or not the muscle imbalance is the cause of symptoms. Once this is established nonoperative treatment should be instituted. If this fails to do good, the patient is at least entitled to know that a safc operation done on the right muscle will do no harm and in practically all cases will secure good restilts. The man who fails to give his patients this chance or who goes so far as to warn them against muscle operators is in my opinion not practicing his specialty fairly either to his patient, to himself or to those specialists who are trying scriously to relieve this class of cases.

\title{
REMOVAL OF FOREIGN BODIES FROM THE EYE.
}

\author{
Frank Altiport, M. D., F. A. C. S., \\ CIIICAGO, ILL.
}

This paper discusses practical points with reference to the diagnosis and removal of foreign bodies lodged in the cyeball, using the publication of McReynolds' vicws as an occasion for the expression of his own.

In the September 13th Number of the A. M. A. Journal appears an article by Dr. John O. McReynolds of Dallas, Texas, on foreign bodies within the eycball. McReynolds' review of the situation is excellent, and takes into consideration almost all ordinary aspects of this interesting and diversified subject. There are, however, some views expressed by Dr. McReynolds that it might be serviceable to discuss with him, and this is the purpose of this review.

Detection BY X-RAYS. McReynolds speaks of objects being so small as to be unnoticed by the X-ray. It would hardly be wise to positvely challenge this statement, but the writcr of this review belicves he has never seen this opinion verified; altho his experience is somewhat extensive in this particular line of work, and he has removed steel particles from the vitrcous so small as to be almost invisible to the naked eye. He has, of course, been deceived, as has probably every eyc surgeon, in the $X$-ray findings; but it has probably never been on account of the size of the foreign body. It has been on account of a poor picture, or an unfortunate head posture, concealing the object behind a piece of thick bone, or an inacurrate $X$-ray reading; but probably never, as has been said before, on account of the size of the object.

McReynolds refers to those puzzling cases where the missile has passed completely thru the eyc, and lodged in the socket behind the globe. Of course, where it is positively ascertained by the $\mathrm{X}$-ray, orbital measurement, and the localizer, that the object is in the orbital tissue, it can, unless excessive inflammatory conditions exist, be safely left pending future developments. But there are puzzling cases, where the object has just passed thru the posterior sclera and is entangled in the tissues immediately connected with the eyeball. In such instances it is often difficult to determine whether the object is inside or outside the scleral structure, which of course involves the question of operation. The writer has, in such doubtful cases sometimes, made use of what might be termed a moving picturethat is, he has liad the patient move the eye two or three times during the 
exposure, to ascertain whether the object moved with the eye or not, and if so the extent of the excursions. If movement was obtained, it indicated at least close proximity of the object to the eye and the wider the excursion the closer the proximity. Of course, this is not positive evidence, but it is, after all, evidence, and may assist in the decision of a doubtful case. Almost all cases can be decided by a careful examination of a good profile and a front view X-ray picture, assisted, where necessary, by exact localization. McReynolds brings up the old question as to the tolerance of small particles within the substance of the lens. Doubtless the lens is quite tolerant of small objects for a while, but after a while lens tissue harboring a foreign body absorbs, and trouble is bound to ensue. After all, why should the object not be removed at once, and thus minimize the danger. The writer is quite certain that no ophthalmic surgeon of experience would allow a foreign body to remain in his lens, if he was confident it could be removed by a magnet, or a cataract operation, or both. Therefore, while it may be assumed that the lens tolcrates a foreign body with some degree of patience, the writer feels that all intraoctlar objects, whether in the lens or elsewhere, should be removed immediately if possible. The longer such objects are allowed to remain, the more dangerous they become, whether, as McReynolds states, they are covered with plastic exudate or not. Any other policy is dangerous in the extreme, and should not be regarded as safe ophthalmic surgery.

Nonmagnetic Bodies. Of coursc, when the removal of intraocular foreign bodies is referred to, we mean, in reality, magnetizable stcel objects. All other fragments present difficult and almost impossible conditions. Such foreign bodics may include nonmagnetizable steel and iron, glass, copper, brass, wood, etc. If such objects are in the anterior chamber, or iris, they may usually be removed by forceps, an iridectomy (containing the foreign body) etc. If the object is in the lens, the lens with the object may be removed by what tecomes practically a cataract operation. But, if objects, uninfluenced by the magnet, are posterior to the lens then their removal becomes a very difficult and extrahazardous operation, and will not be referred to in this review. It is an entirely different subject.

The experience of the writer agrees with McReynolds when he speaks of the infrequency of actually observing glass within the eye. The writer can truthfully say that after many years of fairly extensive experience in tranmatic ocular surgery he has never actually seen a piece of glass in the eyc or conjunctival sac. He has had many cases referred to him, where the cye has been cut, and where the surgeon rendering immediate first aid has said that he has removed glass or some friend has removed glass, but he has never actually seen glass himself. The writer believes that actual glass injuries, especially severe ones, are very rare.

The Hand Magnet. The writer also agrees with McReynolds in his avowed preference for the Sweet hand magnet. He has never seen the Haab magnet remove steel where the Sweet magnet failed. He, therefore, regards the Swcet magnet as sufficient, and much easier handled. It becomes quite hot in a short time, however, and to offset this difficulty he covers the magnet with an overcoat of asbestos. Over this, of course, he slips a sterile bag about the shape of the magnet so that it can be safely handled. Of course, it may be possible that if a surgeon follows the directions of Haab and removes practically all fragments thru the cornea, the strong Haab magnet might be necessary to draw an object from the posterior portion of the vitreous chamber. But the writer removes all fragments, posterior to the lens, thru a scleral opening, and the Sweet magnet has proven sufficient for such work as well as in the removal of fragments in and anterior to the lens thru the cornea. The writer cannot understand why all surgeons do not adopt this rule, for it is cer- 
tainly safer, better surgery and more logical, all things coinsidered, to remove objects located posterior to the lens thru the sclera than to drag them out thru and over the sensitive and important structures located in the anterior portion of the eyeball. The writer has frequently and emphatically expressed his views on this subject and will, thereforc, refrain from expatiating further, except to say that his continued experience has only emphasized his opinions.

Since commencing the use of the Sweet magnet the writer has modified his views concerning the intraocular introduction of magnet points. While he was under the influence of the large clumsy magnets, he became averse to introducing magnet points into the eye, owing to the unwieldy nature of the heavy cumbersome magnets. It seemed like too delicate work for such clephantine instruments. But the Sweet magnet is easily handled and if necessary, the smaller elongated points that come with the magnet may be attached, and carefully introduced inside the eyeball. The writer desires, however, to emphasizc that, in his opinion, no point should be introduced inside the eyeball until all other methods have been first exhausted.

After the scleral incision has been made (which should be ample) the short strong point should be introduced into the opening, and as a rule the steel will promptly come out. The magnet should be held, if possible, directly on a line with the long axis of the splinter, as it, of course, comes out much easier this way. If the steel does not present, the point can be held for some time at the opening and the current frequently snapped on and off. If this does not suffice, the wound may be held open by two little clemagnetized points that I devised years ago. They serve as minute retractors and are held by the two hands of an assistant and are proferable to the two sttures passed thru the two opposite sides of the incision, to hold apart the wound, as suggester by some writers. The magnet may now be replaced, snapped on and off, etc. If this does not suffice, one of the small elongated Swect points may be carefully introduced into the eyeball in the direction of the fragment as indicated by the $\mathrm{X}$-ray picture. The writer believes it unwise to introduce magnet points of any kind inside the eyeball more than one, two, or three times, and not then if possible to avoid it. Each introduction means trauma and possible infection and this should always be remembered. The writer believes that delicate magnet points could be devised, that would be much less awkward to handle than scissors or forceps, but it should not be forgotten that the smaller and more delicate point the weaker will be the magnetizing power.

Localization. Concerning the accurate localization of objects, as spoken of by Dr. McReynolds, the writer is convinced that less elaborate localization is usually sufficient for all practical purposes, altho there are occasional cases where more exact localization is highly desirable. He does not wish to be understand as opposing the important localization methods of Swect and others, but he sincerely feels that if he has access to a clear full facc $X$-ray view and a clear profile $X$-ray vicw that he can, in almost all cases, locate the object with sufficient accuracy for any operative procedure. This saves time, expense and trouble.

Operation. In discussing Dr. McReynolds' paper, Dr. Wm. M. Sweet, whose experience in magnet cases is, of course, very extensive, advocates the scleral route for the removal of steel fragments in almost all cases. He makes a cut in the conjunctiva and undermines it in all directions. $\mathrm{He}$ then holds the conjunctiva apart, by two sutures, one in each side of the incision, and opens the sclera. The writer prefers his own method, which consists in picking up the conjunctiva near the sclerocorneal margin and making a triangular flap with scissors up to the culdesac. This is undermined by expanding the scissors blacles. The triangular flap can then be laid back and a large sclcral arca will be exposed. 
A Graefe knife is then thrust thru the sclera just back of the ciliary region and extended backward to correspond with the size of the foreign body, remembering to make the incision too large rather than too small. After the object has bcen removed by the magnet the conjunctival flap can be placed in position and held there by two fine conjunctival sutures, placed one at each side of the apex of the flap-the apex itself being too close to the cornea to admit of suturing.

Results. The writer wishes also to refer to Dr. Sweet's timely utterance concerning the ultimate result in many of these cases. They are frequently most disappointing and it often happens that, altho the steel is removed and the eye becomes quiet and vision is well restored, a few months hence the eye will become blind and perhaps have to be removed. Still we frequently retain good eyes and good vision and we must not be discouraged because of occasional poor results. As Sweet remarks, the chief factor in securing success consists (aside from good operating), in carly diagnosis, and in the prompt removal of the foreign body. This means the education of laborers and the employers of labor, for most delays originate with them. Back of all this, however, is "Prevention." This means well lighted and well ventilated factories, fitted up with accident preventing machinery, goggles, etc. If such things are installed and used, a vast majority/ of these accidents will not occur, and if prompt and proper action is taken when they do uccur, many eyes will be saved that otherwise will be lost.

\title{
OPHTHALMIC EDUCATION AND TEXT BOOKS.
}

\author{
Clarence Loeb, A.M.; M.D.
}

\author{
CIIICAGO, ILLINOIS.
}

This paper points out certain defects in educational methods, especially as bearing on the study of ophthalmology. It urges the advantage of becoming familiar with diseasc as symptoms rather than knowing it by names; and suggests a modification in text books that would help in this direction. It was read before the American Acadeiny of Ophthalmology and Oto-Laryngology, October, 1919.

Several articles have appeared in the last few years dealing with the question of Ophthalmic Elacation. Various admirable suggestions have been made treating of more thoro instruction in the subject of ophthalmology, advocating more attention to it on the part of those responsible for the curricula of medical colleges, and, in general, emphasizing the importance of a knowledge of ophthalmology for a student intending to do general practice. These papers I do not desire to discuss, except to approve most heartily of anything that will improve medical education, and more especially ophthalmic education. But it does not seem to me that these improvements go far cnough, or rather, it does not seem that they are attacking the prob- lem irom the currect angle. While they would result in improvement, might not greater progress be obtained if somewhat different methods of teaching were employed than those now in use? If we are traveling along a narrow and method-rutted path, is it better to patch up the old one or to survey a new one, if opportunity offers for such a collrse?

1 realize that in advocating a change 1 am running counter to two great forces; that of the inertia which tends to crystillize methods, and that of the opinions of men of far greater experience in teaching than I have had, men who are honestly convinced that they are obtaining the best results with their present mechods. But I submit that they may not be the best men to 